\title{
Griticariográfica
}

\section{Tecnologias digitais no ensino de História - Resenha de "Museus virtuais e jogos digitais: novas linguagens para o estudo da história", de Lynn Rosalina Gama Alves, Alfredo Matta e Helyon Telles}

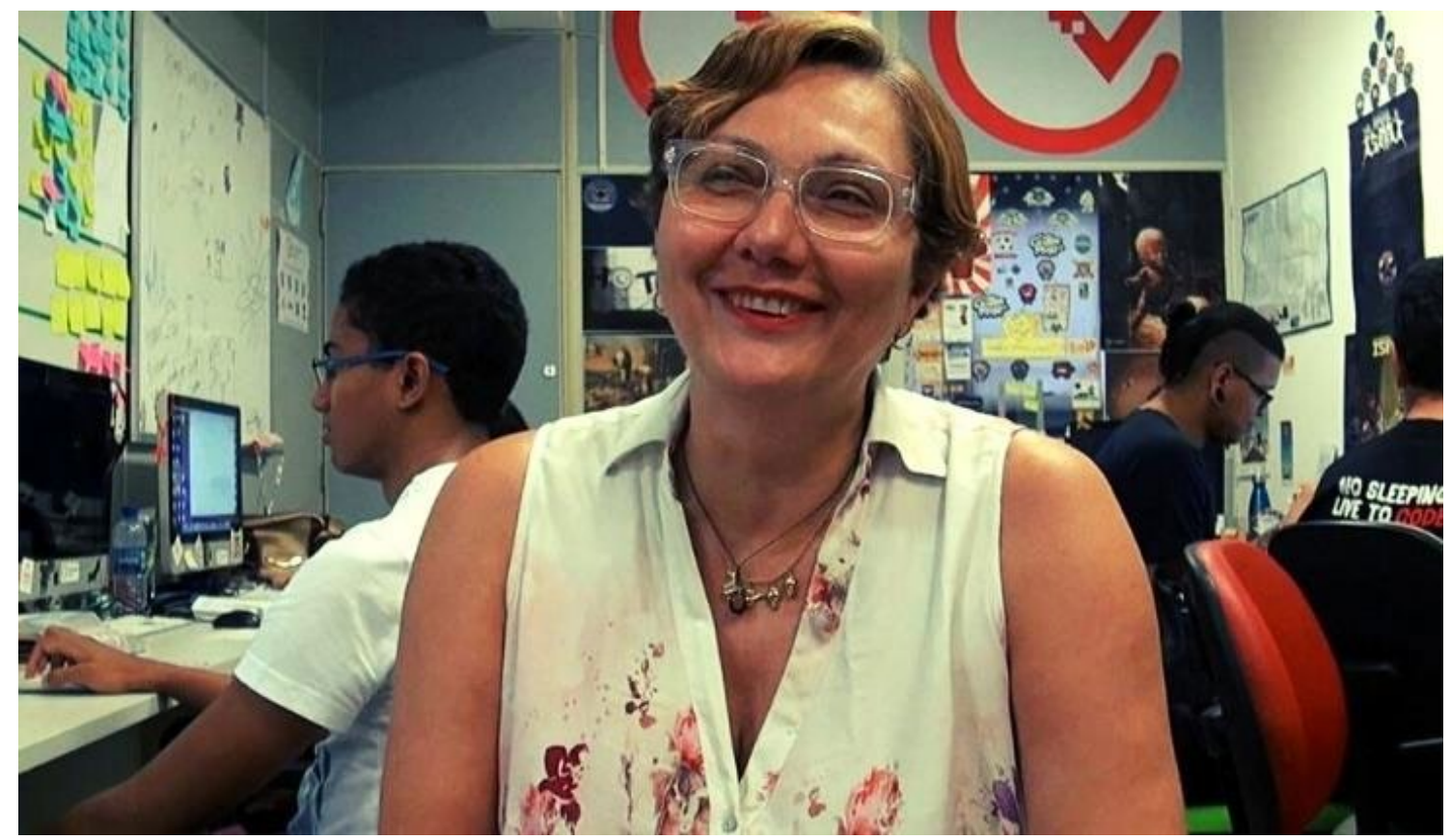

Capacitor (2018)

A obra Museus virtuais e Jogos digitais - Novas linguagens para o estudo da História, de Lynn Alves, Helyon Viana e Alfredo Matta, é um livro sobre recursos digitais para o ensino de História na educação básica com foco na temática da gamificação e dos museus virtuais. O livro é divido em duas partes. A primeira tem sete capítulos e maior incidência de tema nos games. A segunda parte possui cinco capítulos, sendo três dedicados aos museus e dois sobre os jogos de RPG (Role Playing Game). Trata-se de um compêndio destinado à divulgação dos trabalhos dos orientandos do professor Alfredo Matta que atua na área do Ensino de História desenvolvendo práticas de ensino, pesquisa e extensão para o ensino de História, na Universidade do Estado da Bahia. 


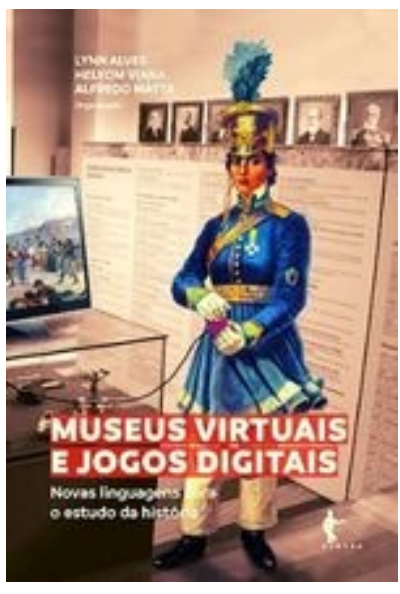

O objetivo principal do livro é incentivar a divulgação dos trabalhos dos intelectuais que pesquisam sobre a temática do ensino de História aplicado à tecnologia. Os autores declaram o desejo de transformar professores portugueses e brasileiros, efetivamente, em protagonistas, que percebam o potencial da aprendizagem história para além da simples memorização.

Os capítulos iniciais da obra apresentam artigos extensos com uma visão metodológica, experimentando procedimentos para colocar o jogador com o papel principal da história e aplicando a educação histórica dos jogos e museus virtuais. O livro é, possivelmente, destinado para professores e pesquisadores da educação básica pois, em alguns dos escritos, é possível localizar assuntos que são destaques desde o período inicial da educação até os anos finais. A obra, todavia, contribui com sugestões de pesquisas para a História e para a grande área da Educação.

Esta primeira parte da obra é um aporte bastante centrado na aprendizagem histórica do aluno, evidenciado pelos primeiros artigos que ressaltam os jogos de protagonismo em primeira pessoa, oferecendo ao jogador a sensação de vivenciar fatos como épocas históricas, monumentos antigos e cenários guerra e pós-guerra, assuntos que fazem parte de séries tanto do ensino fundamental como do ensino médio. São experiências que contribuem para o exercício das metodologias ativas no ensino de História, tirando o aluno do seu lugar passivo e agente receptor de conteúdo para auxiliar relatos da experiência virtual vivenciada, possibilitando que tanto os jogos como os museus virtuais sejam aptos a proporcionar ao aluno essa dinâmica.

O primeiro capítulo foca na experiência de protagonismo do indivíduo em contato com o recurso tecnológico do jogo. Iniciando com uma experiência detalhada sobre a série de jogos uncharted, o jogo, que usa aventura de reunir relíquias e monumentos Históricos como critério para avançar de fase, apresenta várias sugestões pedagógicas sobre como seria possível empregá-lo nas aulas de História, fato afirmado quando o autor descreve como apresentar as relíquias durante as aulas da construção de civilizações antigas.

O segundo e único capítulo desta parte que discorre sobre museus faz um relato de experiências nos museus digitais para a formação da construção social de alunos em idade escolar. O capítulo historiciza o início da formação dos museus e a mudança da sua concepção. $\mathrm{O}$ trecho apresenta alguns museus que funcionam totalmente de maneira digital e também faz a relação dos jogos digitais educativos e o seu uso no ensino.

O capítulo três é uma contribuição do colaborador Helyon Viana Telles, uma comunicação dos games educacionais e a crítica sobre trabalhos de investigação da relação História e jogos eletrônicos brasileiros, artigo focado para o campo da pesquisa. Os outros quatro falam exclusivamente da experiência game e suas contribuições ricas sobre simulações do passado para o jogador em primeira pessoa, entrelaçados pela inteligência artificial e os conhecimentos históricos disponíveis. Como afirma o autor, "as I.A contribuem assim como diz o autor para melhorar a experiência e imersão do usuário nos jogos e nas experiências museais como é o caso dos Histgames (Hist= História;Game=jogo) jogos educacionais focados na disciplina de História."

O Histgame apresentado no artigo desta primeira parte é um jogo de perguntas e respostas sendo apenas uma correta. Ao final do jogo, e com o acúmulo de respostas corretas, os jogadores são classificados por um ranking. A obra não se limita a este tipo 
de jogo. Ela traz uma lista vasta de jogos educacionais para a disciplina na qual professores de quase todas as séries do ensino básico encontrarão sugestões para inserir em suas aulas. Além de relatar o uso dos jogos, os autores correlacionam jogos e assuntos do currículo escolar. Encontramos estas sugestões tanto no corpo do artigo como logo após a conclusão em uma relação em que todos foram analisados.

No capítulo quatro, o livro apresenta uma catalogação de jogos que tem como cenário a Guerra Fria. São descritos a sua construção e o seu uso para uma explanação educacional. Há também índice de games sobre a colonização da América, com personagens na condição de navegadores e escravos, cenários ricos em detalhes da época e aventuras que colocam o jogador como personagem da História. Estes são alguns dos que aparecem neste primeiro extrato. No final de alguns capítulos, os autores se preocuparam em disponibilizar o catálogo dos jogos usados nos estudos para abordar algumas temáticas. É uma pena que nem todos os autores de capítulos procedam da mesma maneira.

Apesar dessas qualidades, uma ausência ganha destaque. No livro, não se debate sobre a aquisição dos recursos e dos meios facilitadores para aplicar tais jogos e visitas em museus para alunos do ensino público, pois são meios que demandam produtos de uso coletivo e para que estes circulem em todos os ambientes escolares é necessário o investimento governamental. Essa falta desperta uma sensação romantizada de que a aplicabilidade destes é algo pessoal de cada professor.

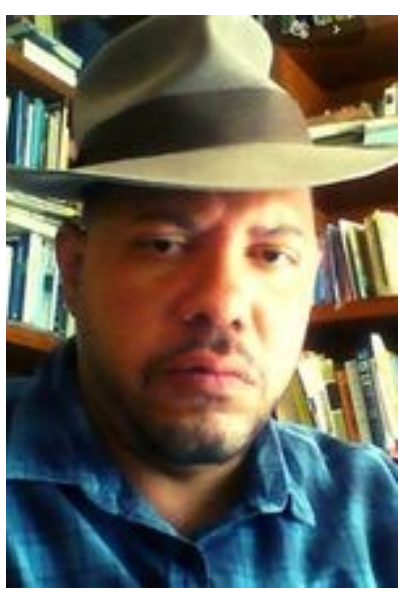

Figura 1 Helyom Telles

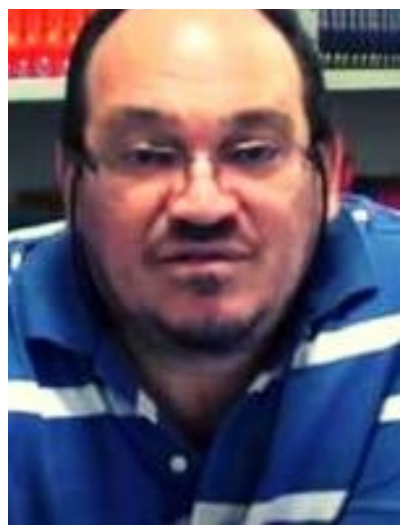

Figura 2 Alfredo Matta

A segunda parte da obra é constituída por artigos um pouco mais curtos e centrados nas teorias e conceitos, formas de usar os jogos e museus virtuais nas aulas e nas pesquisas. Há mais capítulos sobre os museus virtuais e como a experiência de uma vivência dentro desse universo museológico contribui para a construção social do indivíduo.

Para esse tema, são dedicados três dos cinco capítulos do livro. $\mathrm{O}$ primeiro artigo aborda como os museus virtuais contribuem para a aquisição das competências e conhecimentos com a apresentação do projeto UC Digital que é a experiência de espaço museológico a céu aberto com um roteiro préestabelecido de acordo com os interesses de cada turma.

O segundo capítulo possui abordagem um pouco rasa em relação aos jogos digitais e os museus digitais. É um texto que historiciza sobre o conteúdo da História como ciência e tem o objetivo de relembrar que os museus não possuem apenas a função de recurso didático. Museu é um espaço de comunicação a serviço de cultura da comunidade.

O terceiro capítulo explana sobre a temática museológica: o relato de experiência obtida pelo autor em pesquisa dentro do museu 3d do teatro São João da Bahia. Esse texto contribui para ampliar as formas de pesquisas transdisciplinares, pois o estudo foi elaborado com contribuição de diversas áreas como música e arte. O tópico é rico em contribuições para pesquisas e projetos pedagógicos escolares, uma vez que o editor deixa várias inquietações em aberto sobre a sua análise do exercício. 
O quarto capítulo da obra disserta sobre os jogos RPG (Role Playing Game) como instrumento pedagógico para o ensino de História. Este jogo é configurado por narrativas, interpretações e tomadas de decisão. Foi modelado um jogo para desenvolver o pensar Histórico sobre a abolição da escravidão com objetivo de gerar uma aprendizagem crítica e significativa para os alunos participantes. Esse trecho aponta uma crítica sobre metodologias usadas pelos professores de História e as suas aulas tradicionais e expositivas, porém, a falta de recursos e materiais digitais é uma questão de debate coletivo.

O quinto e último capítulo trata do uso dos mapas cartográficos em game para o uso do RPG Histórico. O nome do jogo aqui relatado é RPG 2 de julho, uma referência direta ao movimento de independência do Brasil na Bahia, simulando várias fases da guerra . O objetivo deste recurso é ampliar as possibilidades pedagógicas para o ensino utilizando as tecnologias digitais. É claramente mais um fomento ao uso de metodologias ativas para a História. O capítulo possui contribuição significativa e marcante, narrando, além dos usos, a importância de colocar o aluno no papel interativo do jogador adquirindo uma aprendizagem participativa.

$\mathrm{O}$ incentivo à divulgação de recursos tecnológicos para o ensino de História é ratificado do início ao fim desta obra, fazendo cumprir objetivos anunciados pelos autores. Contudo, senti falta de questionamentos sobre o acesso para estes meios de maneira inclusiva e colaborativa. Apenas um fragmento da segunda parte faz uma abordagem superficial sobre a questão, porém, aponta o docente como principal autor da falta de uso e ampliação destes meios. $\mathrm{O}$ enfrentamento dessas questões permitiria reduzir a negativa destes recursos e atividades em sala de aula. Apesar desses senões, a obra em questão deve ser lida pelos pedagogos, professores de História e Geografia e pesquisadores da grande área da Educação, Historiadores e graduandos da área de licenciaturas, dado o seu potencial para divulgar métodos digitais e tecnológicos para práticas do ensino de História na sala de aula, e o esforço e preocupação em divulgar estas pesquisas que é algo ainda em crescimento no Brasil.

\section{Sumário de Museus virtuais e jogos digitais: novas linguagens para o estudo da história}

- A História e suas interfaces - Lynn Rosalina Gama Alves e Helyom Viana Telles

○ Parte I. Museus, jogos digitais e o Ensino de História

- Games e História: monumentos digitais - Ivana Carolina Alves da Silva Souza e Lynn Rosalina Gama Alves

- Jogar e compartilhar: por uma descrição densa dos jogos eletrônicos baseados em simulações do passado - Helyon Viana Telles

- Games e Geopolítica: uma análise sobre a influência do discurso geoestratégico norte-americano em Supreme Ruler Cold War - Diogo Trindade Alves de Carvalho

- História em jogo: aspectos da colonização da América e elogio do colonizador Hezrom Vieira Costa Lima

- Inteligência artificial, jogos digirais e Ensino de História no século XXI: multiversos e transformações educacionais - Bergston Luan Santos e Ecídio Pimenta Arruda

- Os jogos digitais e o ensino de História: o caso do Histgame - Marcella Albaine Farias da Costa, Luisa da Fonseca Tavares, Diana Jane Barbosa da Silva e Rayane de Castro Guedes 
- Parte II. Museus Virtuais, RPG e o ensino de História

- Museus virtuais interativos enquanto artefactos digitais para a aquisição de competências e conhecimentos: o Projeto UC Digital - Sara Dias-Trindade, Ana Isabel Ribeiro e José Antônio Moreira

- Museu Virtual em 3D, Teatro São João da Bahia: uma abordagem socioconstrutivista Maria Antonia Lima Gomes, Alfredo Eurico Rodrigues Matta e Lucas Robato

- RPG Liberdade: instrumento pedagógico para o ensino de História - Antônio Lázaro Pereira de Souza

- Uso de mapa cartográfico em game RPG Histórico - Josenilda Mesquita, Fabricio Moreira e Alfredo Eurico Rodrigues Matta

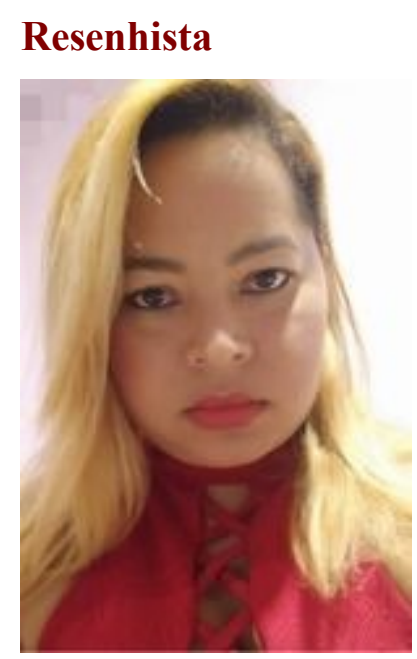

Marcia Evangelista da Silva - Mestre em Ensino de História pela Universidade Federal de Sergipe, publicou

"Alfabetização histórica e a BNCC em escolas municipais de Barra dos Coqueiros/Sergipe", "Ensino-aprendizagem de História nos Anos Iniciais do Ensino Fundamental: Estudo de caso em escolas municipais de Barra dos Coqueiros/Sergipe" e "Caminhos da aprendizagem histórica: ensino, reflexão e ação". E-mail: marciaevangelistasilv@outlook.com

\section{Referências desta resenha}

ALVES, Lynn Rosalina Gama; MATTA, Alfredo; TELLES, Helyon (Org.) Museus virtuais e jogos digitais: novas linguagens para o estudo da história. Salvador: EDUFBA, 2019. Resenha de: SANTOS, Marcia Evangelista da Silva. Tecnologias digitais no Ensino de História. Crítica Historiográfica. Natal, v.2, n.1, jan./fev. 2022. Disponível em: https://www.criticahistoriografica.com.br/1943/

\section{Baixar esta resenha em PDF}

(C) - Os autores que publicam em Crítica Historiográfica concordam com a distribuição, remixagem, adaptação e criação a partir dos seus textos, mesmo para fins comerciais, desde que lhe sejam garantidos os devidos créditos pelas criações originais. (CC BY$\mathrm{SA})$ 